\title{
Micronodular thymic carcinoma with lymphoid hyperplasia: a clinicopathological and immunohistochemical study of five cases
}

\author{
Annikka Weissferdt and Cesar A Moran \\ Department of Pathology, MD Anderson Cancer Center, Houston, TX, USA
}

\begin{abstract}
Five cases of an unusual variant of thymic carcinoma are described, which represent the counterpart of the socalled micronodular thymoma with lymphoid hyperplasia. The patients were three men and two women aged 42-78 years (mean 64 years). Three patients were asymptomatic and the tumors were found incidentally on chest radiographs performed for unrelated reasons. Two patients complained of dyspnea, chest pain and shortness of breath prompting further investigations. The tumors ranged in size from 3.2 to $10.0 \mathrm{~cm}$ and were described as infiltrative masses often invading adjacent structures. Prominent cystic changes were not identified. Histologically, the neoplasms were composed of epithelial tumor cells arranged in a micronodular growth pattern set in a stroma showing florid lymphoid hyperplasia. Contrary to micronodular thymoma, the epithelial cell component of the present cases showed unequivocal signs of malignancy characterized by cytological atypia and increased mitotic activity. Immunohistochemical studies showed the lymphoid component to be of mixed B- and T-cell lineage. None of the patients had a history of myasthenia gravis or other autoimmune disorder. Follow-up revealed that 4 patients were alive and well 3-26 months after diagnosis while 1 patient was dead of disease 21 months after diagnosis. The tumors in this series represent a distinct subtype of thymic carcinoma histologically strongly resembling micronodular thymoma with lymphoid hyperplasia. Awareness of this type of thymic carcinoma is important in order not to dismiss this tumor for a neoplasm of lower-grade malignancy.

Modern Pathology (2012) 25, 993-999; doi:10.1038/modpathol.2012.40; published online 2 March 2012
\end{abstract}

Keywords: anterior mediastinum; lymphoid hyperplasia; micronodular thymoma; thymic carcinoma

Thymic epithelial neoplasms are tumors that can show high morphological variability. Given the overall rarity of these tumors, their diagnosis may be challenging, especially as the pathologist is often confronted with diagnostic material derived from small mediastinoscopic biopsies. Although thymomas are tumors of low-grade malignant potential characterized by an epithelial cell component with no overt cytological atypia and a variable number of immature T-lymphocytes, thymic carcinomas demonstrate frank malignant changes of the epithelial cells and lack an immature T-cell population.

Thymic carcinoma in particular is a tumor that displays a wide range of morphological patterns,

Correspondence: Dr A Weissferdt, MD, FRCPath, Department of Pathology, MD Anderson Cancer Center, Houston, TX 77030, USA.

E-mail: aweissferdt@doctors.org.uk

Received 22 December 2011; revised 12 January 2012; accepted 12 January 2012; published online 2 March 2012 which is reflected in the many different subtypes observed. ${ }^{1,2}$ The cases herein described represent an unusual variant of thymic carcinoma characterized by a micronodular growth pattern and a prominent lymphoid stroma. Overall, the features are highly reminiscent of the so called micronodular thymoma with lymphoid hyperplasia, a distinct type of spindle cell thymoma initially described by Suster in 1999. ${ }^{3}$ A detailed study of the micronodular growth pattern and prominent lymphoid stroma in relation to thymic carcinoma, however, has not been addressed.

\section{Materials and methods}

Five cases of thymic carcinoma with a micronodular growth pattern and prominent lymphoid hyperplasia were retrieved from the files of the Department of Pathology, MD Anderson Cancer Center, Houston or the personal consultation files of one of the authors 
(CAM). Histological material derived from thymectomy specimens was evaluated in every case. Two to twenty hematoxylin and eosin-stained sections were available for review in each case. Representative paraffin blocks or unstained sections were available for immunohistochemical studies in three cases. Immunohistochemical studies for CD20 (Dako, Carpinteria, CA, USA; 1:1400), CD3 (Dako1:100), TdT (Dako; 1:20), Kappa antibody (Dako; 1:20 000), and Lambda antibody (Dako; 1:20 000) were performed with concurrent adequate controls. Clinical follow-up information was obtained from the medical charts or by contacting the referring physicians.

\section{Results}

\section{Clinical Findings}

The clinical findings are summarized in Table 1. The patients were three men and two women aged 42-78 years (mean age 64 years). Three patients did not have any symptoms and the tumors were incidental findings on chest radiographs performed for routine physical examinations. Two patients were symptomatic with dyspnea, chest pain and shortness of breath. Clinical and radiological investigations did not reveal any tumor elsewhere and thymectomy was performed in all cases. To the best of our knowledge, complete surgical resection was achieved in all cases. None of our patients had a history of myasthenia gravis or any other autoimmune disease and none had received chemotherapy for their thymic tumors or other neoplasms.

\section{Gross Findings}

All tumors were mass-like mediastinal lesions with ill-defined borders measuring $3-10 \mathrm{~cm}$ in maximum dimension. The cut surface was tan yellow in color and of firm or indurated consistency. Invasion into the pleura or lung parenchyma was noted in two cases. Areas of hemorrhage or necrosis were not identified grossly and nor was any prominent cystic component.

\section{Histological Findings}

All tumors showed similar histological findings. On low power, the most striking finding was a micronodular growth pattern characterized by multiple small tumor nodules separated by an abundant lymphoid stroma (Figure 1a). In some areas, the tumor nodules coalesced to form more sheet-like, elongated or solid areas of tumor cells. In some areas infiltration of adjacent pleura or lung parenchyma was observed.

On higher power, the tumor cells in three cases were large and round to oval shaped with vesicular nuclei, conspicuous eosinophilic nucleoli and abundant eosinophilic cytoplasm. Focal keratinization was seen in three cases consistent with squamous differentiation (Figure 1b); clear cell change toward the center of the tumor nests was apparent in a single case. The other two tumors were of spindle-cell carcinoma type displaying neoplastic epithelial cells that had a prominent fusiform appearance and contained nuclei with an open-chromatin pattern and punctuate nucleoli (Figure 1c). The surrounding lymphoid stroma in all cases was composed of a dense proliferation of small lymphocytes and contained numerous lymphoid follicles with germinal centers (Figure 2a). Scattered lymphocytes were sprinkled within the micronodular carcinomatous component. In one case, central foci of hyalinization were identified within the germinal centers (Figure 2b). Plasma cells were present intermixed with the lymphocytes in all cases. Comedo-like areas of necrosis were present in two cases and the mitotic activity ranged from 5 to 14 mitoses per 10 highpower fields (Figure 2c). In one case, areas of transition with a more bland appearing epithelial proliferation devoid of cytological atypia, or mitotic activity were present, probably representing transition with a thymoma component.

\section{Immunohistochemical Findings}

Immunohistochemical studies were performed in three cases in order to characterize the lymphoid component. In all three cases the lymphoid stroma was composed mainly of mature B lymphocytes $(\mathrm{CD} 20+)$ especially highlighting the follicles and germinal centers (Figure 3a). Mature CD3 +/TdTT-lymphocytes were also numerous (Figure 3b), however, immature $\mathrm{T}$ cells were not identified in any of the cases. Stains for kappa and lambda showed a polyclonal staining pattern with equal proportions of kappa and lambda positive cells (Figures 3c and d).

Table 1 Clinical features of five patients with micronodular thymic carcinoma

\begin{tabular}{|c|c|c|c|c|c|}
\hline Case & Sex & Age & Symptoms & Tumor size $(\mathrm{cm})$ & Follow-up \\
\hline 1 & $\mathrm{~F}$ & 61 & Incidental finding & 5.0 & A\&W at 3 months \\
\hline 2 & M & 78 & Incidental finding & 3.2 & $\mathrm{~A} \& \mathrm{~W}$ at 26 months \\
\hline 3 & $\mathrm{M}$ & 71 & Chest pain, SOB & 10.0 & A\&W at 26 months \\
\hline 4 & $\mathrm{~F}$ & 67 & Dyspnea, chest pain & NK & DOD at 21 months \\
\hline 5 & $\mathrm{M}$ & 42 & Incidental finding & NK & $\mathrm{A} \& \mathrm{~W}$ at 24 months \\
\hline
\end{tabular}

F: female; M: male; SOB: shortness of breath; NK: not known; A\&W: alive and well; DOD: died of disease. 

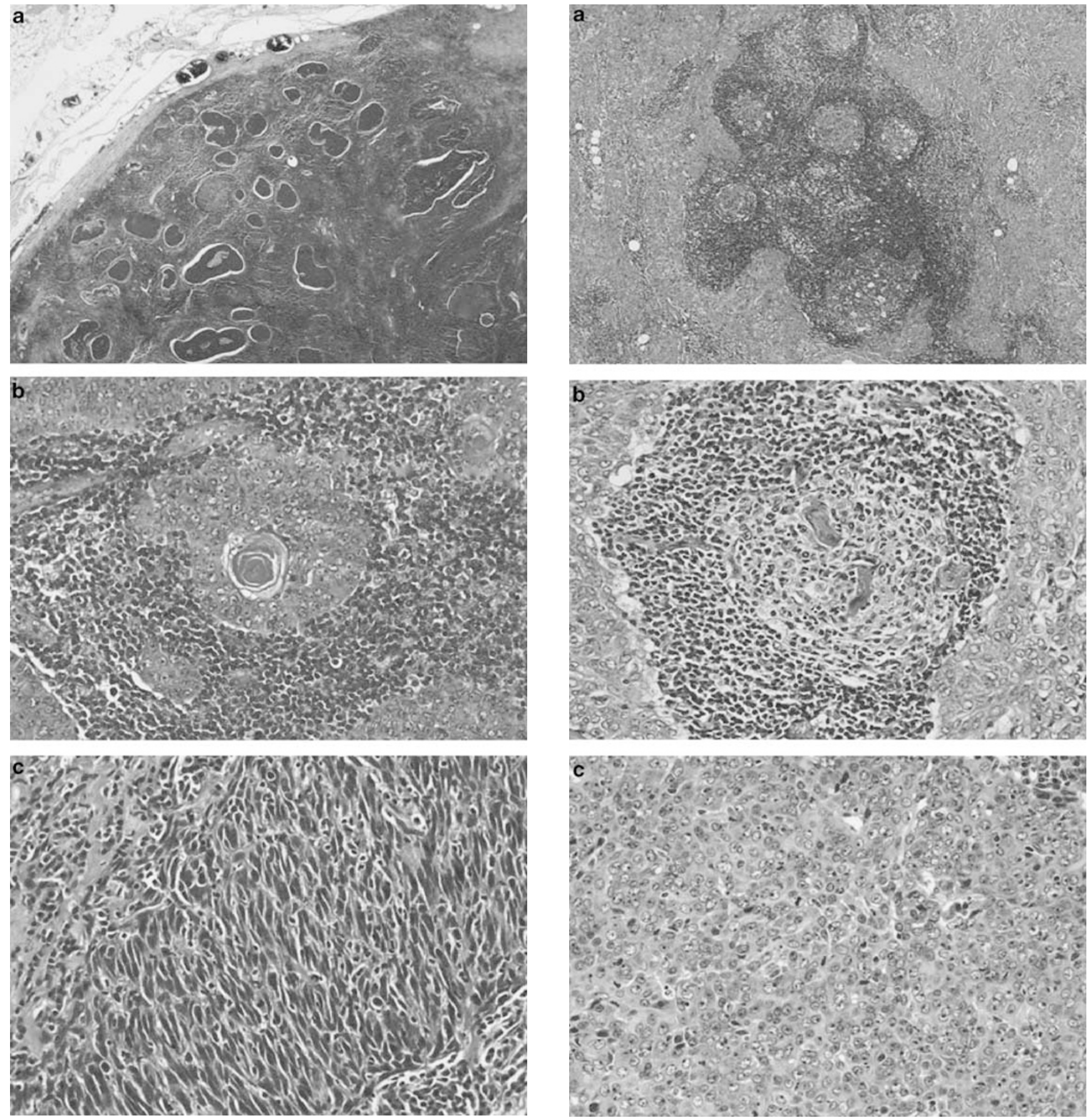

Figure 1 (a) Low-power view of micronodular thymic carcinoma characterized by small tumor nodules separated by an abundant lymphoid stroma. (b) Foci of keratinization in micronodular thymic carcinoma showing squamous differentiation. (c) Highpower view of micronodular thymic carcinoma composed of spindled tumor cells.

\section{Follow-Up}

Follow-up available for all five patients revealed that four patients were alive and well with no evidence of recurrence 3-26 months after the initial diagnosis. One patient died of thymic carcinoma 21 months after the tumor was detected.
Figure 2 (a) Lymphoid follicles with prominent germinal centers are a characteristic finding in micronodular thymic carcinoma. (b) Hyalinization within germinal centers was identified in one case. (c) Cytological atypia and mitotic activity in micronodular thymic carcinoma.

\section{Discussion}

We herein describe five cases of an unusual variant of thymic carcinoma characterized by a micronodular growth pattern, overt malignant cytological features and a prominent lymphoid stroma containing numerous germinal centers. The overall features 

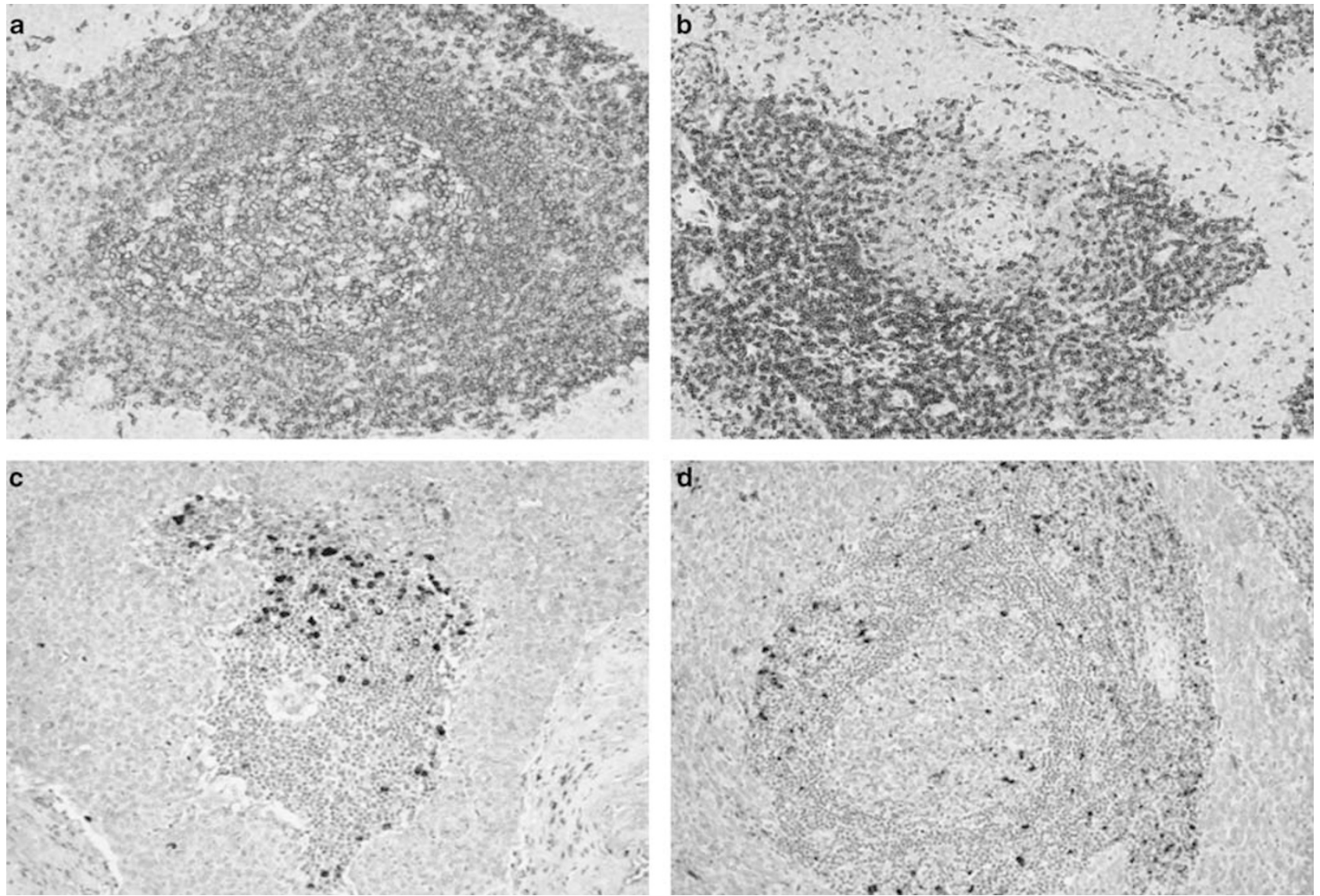

Figure 3 (a) CD20 highlighting B lymphocytes in germinal centers and surrounding lymphoid stroma. (b) T lymphocyte component in lymphoid stroma decorated by CD3 immunostaining. (c) Kappa antibody showing a positive reaction in scattered lymphoid cells. (d) Occasional lymphoid cells also express lambda antigen.

are very similar to those described for a distinct variant of thymoma, the so-called micronodular thymoma with prominent lymphoid hyperplasia. This type of thymoma is uncommon representing less than $5 \%$ of all thymomas. ${ }^{4,5}$ Since the first description of this neoplasm by Suster, ${ }^{3}$ only few series and case reports have been presented in the literature. ${ }^{4-8}$ Micronodular thymomas with prominent lymphoid hyperplasia are usually encapsulated or minimally invasive tumors histologically characterized by a proliferation of small tumor nodules separated by an abundant lymphoid stroma with prominent germinal centers. The individual tumor nodules are composed of spindle cells containing oval nuclei that lack cytological atypia or mitotic activity. The surrounding lymphoid stroma is composed of small lymphocytes and prominent germinal centers. Occasional plasma cells can be identified in the stromal component and scattered lymphocytes may also be seen in the tumor nodules. ${ }^{3}$ Although in the original description the lymphoid component comprised almost exclusively B-cells with only few scattered immature T-cells in the tumor nodules, ${ }^{3}$ in subsequent series, the lymphoid elements were found to be composed of a mix of B- and T-cells. ${ }^{4,5}$ Isolated cases of this tumor showing overt malignant changes of the epithelial cells were identified in two of the reported series. Among Suster's cases, ${ }^{3}$ a single case showed transition from bland spindle cells to a poorly differentiated tumor cell population composed of irregular tumor islands with large hyperchromatic nuclei and prominent nucleoli, frequent mitotic figures and foci of comedo-type necrosis. Two more cases showing similar features were identified in Tateyama's ${ }^{8}$ series of 11 cases. The respective authors interpreted these three cases to represent lymphoepithelioma-like thymic carcinoma. ${ }^{3,8}$ In this context, another study requires closer examination. In 2005, Nonaka et $a l^{9}$ described a series of five cases of what they called 'undifferentiated large cell carcinoma of the thymus associated with Castleman disease-like reaction'. These tumors were portrayed as an undifferentiated large cell type of thymic carcinoma accompanied by an inflammatory infiltrate with the morphological features of hyaline vascular-type Castleman disease. These tumors share some histological features with our cases but differ in others. Both, our cases and those described by Nonaka et $a l^{9}$ demonstrate highgrade thymic carcinomas closely associated with a prominent lymphoid stroma containing lymphoid 
follicles with germinal centers. Contrary to our cases, in Nonaka's series the tumors were classified as 'undifferentiated large cell carcinomas' in some areas resembling lymphoepithelioma-like carcinoma. Spindling of the tumor cells or squamous differentiation was not reported. In addition, one of the most striking features of our cases, the distinct micronodular growth pattern was not mentioned in that study. Another finding emphasized in Nonaka's series was the striking Castleman disease-like features of the inflammatory cell infiltrate characterized by an onion-skin pattern of mantle zone lymphocytes, germinal centers devoid of lymphocytes and prominent interfollicular vasculature. Although one of our cases showed focal hyalinization of the germinal centers, stronger support for the hyaline type of Castleman disease was not present in our cases. Nevertheless, the possibility that all those tumors belong to the same spectrum of neoplasms cannot be entirely excluded. However, if this proves to be the case, the term 'micronodular thymic carcinoma with lymphoid hyperplasia' is preferable to describe these tumors due to the striking resemblance to micronodular thymoma with lymphoid B-cell hyperplasia.

Of note, no tumor deaths were reported for any of the patients with micronodular thymoma despite obvious cytological malignancy in a small number of cases, ${ }^{3,4,6-8}$ nor was there mortality in any of the cases described by Nonaka et al. ${ }^{9}$

Our five cases differed from micronodular thymoma by way of showing unequivocal signs of malignancy, ie, cytological atypia, increased mitotic activity and foci of comedo-type necrosis (Table 2). In keeping with the previous cases showing malignant cytology, our tumors are interpreted to represent thymic carcinoma, and based on the striking similarity to the rest of the features, we believe that this type of thymic carcinoma represents the outright malignant counterpart of micronodular thymoma with lymphoid hyperplasia ('micronodular thymic carcinoma with lymphoid hyperplasia'). An important observation, however, is that in our cases, the malignant epithelial component did not demonstrate the typical morphology of lymphoepithelioma-like carcinoma (syncytial sheets of tumor cells, large vesicular nuclei with open chromatin and prominent nucleoli, dense lymphoplasmacytic infiltrate in the stroma, as well as intimately admixed with carcinoma cells). Our cases were rather classified as squamous cell carcinoma in three cases and spindle-cell carcinoma in the other two cases. In our cases the lymphoid component was rather sharply separated from the tumor nodules and, although lymphocytes were identified within tumor islands, this infiltrate fell short of the typical dense population of lymphoid cells intimately admixed with carcinoma cells in lymphoepithelioma-like carcinoma. Another feature that is often seen in association with micronodular thymoma but was lacking in all of our cases, is the presence of a prominent cystic component. Seven out of eighteen cases in Suster series $^{3}$ and four out of six cases in the study of Thomas de Montpreville et $a l^{5}$ showed prominent cyst formation, presumed to represent dilated perivascular spaces.

In the thymus, the presence of lymphoid hyperplasia with germinal center formation is usually seen in patients with myasthenia gravis or other autoimmune disorders ${ }^{10-12}$ but has also been described in thymic seminomas ${ }^{13,14}$ or multilocular thymic cysts. ${ }^{15}$ It has been speculated that the striking lymphoid hyperplasia in micronodular thymoma is either a host response to tumor antigens or a tissue response to unrelated intrathymic antigens. $^{3,8}$ Similar deliberations regarding the pathogenesis of lymphoid hyperplasia also apply to micronodular thymic carcinomas. In keeping with the patient population of micronodular thymoma, none of the patients in the current series had a

Table 2 Comparison of clinical and pathological features of micronodular thymoma ${ }^{3}$ and micronodular thymic carcinoma

\begin{tabular}{|c|c|c|c|c|c|c|c|c|}
\hline & Sex & Age & $\begin{array}{l}\text { Clinical } \\
\text { presentation }\end{array}$ & $\begin{array}{c}\text { Tumor } \\
\text { size }(\mathrm{cm})\end{array}$ & Gross features & Histological features & $\begin{array}{l}\text { Mitotic } \\
\text { activity }\end{array}$ & Prognosis \\
\hline $\begin{array}{l}\text { Micronodular } \\
\text { thymoma }\end{array}$ & $\mathrm{M}>\mathrm{F}$ & $41-60$ & Incidental & $3-10$ & $\begin{array}{l}\text { Circumscribed } \\
\text { masses; often } \\
\text { cystic }\end{array}$ & $\begin{array}{l}\text { Bland spindle cells with } \\
\text { elongated nuclei and } \\
\text { occasional small nucleoli; } \\
\text { lymphoid stroma composed } \\
\text { of B-and T-lymphocytes } \\
\text { and germinal centers }\end{array}$ & None & Good \\
\hline $\begin{array}{l}\text { Micronodular } \\
\text { thymic } \\
\text { carcinoma }\end{array}$ & $\mathrm{M}>\mathrm{F}$ & $42-78$ & $\begin{array}{l}\text { Incidental or } \\
\text { chest pain, } \\
\text { dyspnea, } \\
\text { shortness of } \\
\text { breath }\end{array}$ & $3-10$ & $\begin{array}{l}\text { Invasive, ill- } \\
\text { defined tumors }\end{array}$ & $\begin{array}{l}\text { Spindle or squamous cell } \\
\text { carcinoma cells composed } \\
\text { of fusiform or plump } \\
\text { epithelioid cells; nuclear } \\
\text { pleomorphism; open } \\
\text { vesicular chromatin with } \\
\text { prominent nucleoli; } \\
\text { lymphoid stroma composed } \\
\text { of B-and T-lymphocytes } \\
\text { and germinal centers }\end{array}$ & $\begin{array}{l}5-14 / 10 \\
\mathrm{HPF}\end{array}$ & $\begin{array}{l}\text { Guarded; } \\
\text { probably } \\
\text { more like } \\
\text { convential } \\
\text { thymic } \\
\text { carcinoma }\end{array}$ \\
\hline
\end{tabular}

M: male; F: female; HPF: high-power field. 
history of myasthenia gravis or other autoimmune disorder. Therefore, the above hypotheses appear to be valid also for patients with micronodular thymic carcinoma.

Although the B cells in micronodular thymoma were initially found to be polyclonal in nature, ${ }^{3}$ a more recent study has identified a high proportion of micronodular thymomas containing intratumoral monoclonal B-cell populations and even low-grade lymphoma. ${ }^{4}$ The authors concluded that abnormal chemokine expression by the epithelial cells of micronodular thymoma may induce the emergence of monoclonal B cells and subsequent development of thymic lymphoma. Therefore, although in our cases the lymphoid component was polyclonal in nature, the possibility of these tumors harboring a low-grade lymphoma should be considered.

Clinical follow-up showed that four patients were alive without evidence of tumor recurrence 3-26 months after diagnosis (mean 20 months) while one patient had succumbed to disease 21 months after the lesion was detected. Interestingly, all described cases of micronodular thymic epithelial neoplasms, including the three previously reported cases showing malignant cytology and the cases reported by Nonaka et $a l^{9}$ have shown a favorable outcome with no reported tumor deaths., ${ }^{3,6,8}$ Whether lymphoid hyperplasia can be considered as a host response leading to improved survival, a phenomenon described for other lymphoid rich carcinomas $^{16}$ remains to be determined. In the meantime, although follow-up period for our patients is rather short, tumor-related deaths do exist and the survival appears to be similar to those patients with the more conventional types of thymic carcinoma. ${ }^{17-19}$

One of the most important issues to highlight is the differential diagnosis for micronodular thymic carcinoma. Particular attention should be paid to the cytological features of the epithelial tumor cells when dealing with a thymic neoplasm showing a micronodular growth pattern and prominent lymphoid stroma as this appears to be the only discriminating factor in the differential diagnosis of micronodular thymoma and micronodular thymic carcinoma. Prominent nuclear pleomorphism, increased mitotic activity and the presence of comedotype necrosis warrant a diagnosis of thymic carcinoma in this context. When dealing with resection specimens, thorough sampling is also advised, as transitions from thymoma to thymic carcinoma do exist in these tumors as seen in one of our cases and in previous studies. ${ }^{3}$ Awareness of the existence of micronodular thymic carcinoma is also important not to mistake this tumor for involvement of mediastinal lymph nodes by metastatic carcinoma or sarcoma. Clinical history is very important in this context as the presence of an isolated anterior mediastinal mass and the absence of any tumor elsewhere will lead to the correct diagnosis. Lastly, the presence of a malignant epithelial component and stromal lymphoid hyper- plasia, respectively, allows differentiation from more conventional thymic carcinoma on the one hand or pure lymphoid hyperplasia on the other.

In summary, our five cases of thymic carcinoma appear to represent the malignant counterpart of micronodular thymoma with lymphoid hyperplasia. Awareness of the existence of micronodular thymic carcinoma is essential for the differential diagnosis of anterior mediastinal neoplasms in order not to confuse this tumor for its lower grade counterpart or metastatic disease to the mediastinal compartment. Longer follow-up in a higher number of cases is necessary to obtain more data regarding the prognosis for patients with these tumors.

\section{Disclosure/conflict of interest}

The authors declare no conflict of interest.

\section{References}

1 Moran CA, Suster S. Thymic carcinoma: current concepts and histologic features. Hematol Oncol Clin North Am 2008;22:393-407.

2 Suster S. Thymic carcinoma: update of current diagnostic criteria and histologic types. Semin Diagn Pathol 2005;22:198-212.

3 Suster S, Moran CA. Micronodular thymoma with lymphoid B-cell hyperplasia: clinicopathologic and immunohistochemical study of eighteen cases of a distinctive morphologic variant of thymic epithelial neoplasm. Am J Surg Pathol 1999;23:955-962.

4 Ströbel P, Marino M, Feuchtenberger M, et al. Micronodular thymoma: an epithelial tumour with abnormal chemokine expression setting the stage for lymphoma development. J Pathol 2005;207:72-82.

5 Thomas De Montpréville V, Zemoura L, Dulmet E. Thymoma with epithelial micronodules and lymphoid hyperplasia: six cases of a rare and equivocal subtype. Ann Pathol 2002;22:177-182.

6 El MF, Braham E, Ayadi A, et al. Micronodular thymoma with lymphoid stroma: report of two cases and particular association with thymic lymphoid hyperplasia in one case. Pathology 2006;38:586-588.

7 Mende S, Moschopulos M, Marx A, et al. Ectopic micronodular thymoma with lymphoid stroma. Virchows Arch 2004;444:397-399.

8 Tateyama H, Saito Y, Fujii Y, et al. The spectrum of micronodular thymic epithelial tumours with lymphoid B-cell hyperplasia. Histopathology 2001;38:519-527.

9 Nonaka D, Rodriguez J, Rollo JL, Rosai J. Undifferentiated large cell carcinoma of the thymus associated with Castleman disease-like reaction: a distinctive type of thymic neoplasm characterized by an indolent behavior. Am J Surg Pathol 2005;29:490-495.

10 Hutchins GM, Harvey AM. The thymus in systemic lupus erythematosus. Bull Johns Hopkins Hosp 1964;115:355-378.

11 Moran CA, Suster S, Gil J, et al. Morphometric analysis of germinal centers in non-thymomatous patients with myasthenia gravis. Arch Pathol Lab Med 1990;114: 689-691.

12 Tamaoki N, Habu S, Kameya T. Thymic lymphoid follicles in autoimmune diseases. II. Histological, 
histochemical and electron microscopic studies. Keio J Med 1971;20:57-68.

13 Moran CA, Suster S, Przygodzki RM, et al. Primary germ cell tumors of the mediastinum: II. Mediastinal seminomas-a clinicopathologic and immunohistochemical study of 120 cases. Cancer 1997;80:691-698.

14 Suster S, Moran CA. Malignant thymic neoplasms that may mimic benign conditions. Semin Diagn Pathol 1995;12:98-104.

15 Suster S, Rosai J. Multilocular thymic cyst: an acquired reactive process. Study of 18 cases. Am J Surg Pathol. 1991;15:388-398.
16 Watanabe H, Enjoji M, Imai T. Gastric carcinoma with lymphoid stroma. Its morphologic characteristics and prognostic correlations. Cancer 1976;38:232-243.

17 Lee CY, Bae MK, Park IK, et al. Early Masaoka stage and complete resection is important for prognosis of thymic carcinoma: a 20-year experience at a single institution. Eur J Cardiothorac Surg 2009;36:159-162.

18 Ogawa K, Toita $\mathrm{T}$, Uno $\mathrm{T}$, et al. Treatment and prognosis of thymic carcinoma: a retrospective analysis of 40 cases. Cancer 2002;94:3115-3119.

19 Suster S, Rosai J. Thymic carcinoma. A clinicopathologic study of 60 cases. Cancer 1991;67:1025-1032. 